\title{
CD44v9 and CD98hc is the marker of cancer stem cells in HNSCC
}

\author{
Yohei Kawasaki ${ }^{*}$ and Yasufumi Omori ${ }^{2}$ \\ ${ }^{1}$ Department of Otorhinolaryngology, Head and Neck Surgery, Akita University Graduate School of Medicine, Japan \\ ${ }^{2}$ Department of Molecular and Tumor Pathology, Akita University Graduate School of Medicine, Japan
}

Cancer stem cells are the most important targets for cancer therapy. Prince et al. report CD44 is the cancer stem cell marker in HNSCC [1]. But various isoforms can be found in CD44, so it is unclear that which variant is the most important. One of characteristic of cancer stem cell is the radio-resistance. Various HNSCC cell lines are irradiated and we established radio-resistant cell line. After irradiation, the expression of CD44v9 increased in all HNSCC cell lines [2]. At present, the importance of CD44v9 is being studies. CD44v9 is expressed in cancer stem cells and functions to enhance the oxidative stress avoidance mechanism that causes resistance to treatment. This indicates that oxidative stress is important for the survival and proliferation of tumor cells, such stress has dual effects of inducing not only differentiation but also cell death when a certain threshold value is exceeded. In addition, in cell membranes, CD44v9 binds to $\mathrm{xCT}$, which is a light chain subunit system xc-, a transporter that takes cysteine into cells.

Moreover, we take notice of CD98 heavy chain. Recently, it has been reported that CD98 is one of the cancer stem cell markers [3].Recent advancements in molecular biological research that the molecular entity of the amino acid transporter system is a membrane-penetrating glycoprotein belonging to the solute carrier (SLC) 3 family. It has been also reported that it is a multifunctional molecule involved in the influx of $\mathrm{Ca}^{2+}$ into the cell and activation of integrin. It has become clear that the molecular entity is heterodimeric transporter comprising an accessory submit of 4F2hc (CD98hc/SLC3A2) and a catalytic subunit of the 12-transmembrane domain amino acid transporter (LAT1) that belongs to the SLC7 family.

After irradiation, the expression of CD98hc is significantly increased in all cell lines. The binding by which the CD98hc becomes a chaperone molecule promotes the formation of reduced GSH, which is an antioxidant, by increasing the stability of $\mathrm{xCT}$ at the membrane. GSH functions as a scavenger of reactive oxygen species (ROS) in

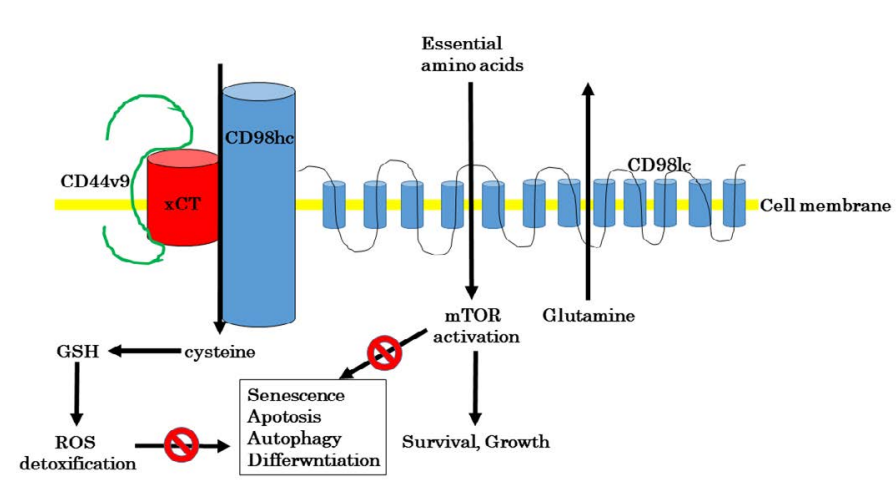

Figure 1. Cancer stem cells express CD44v9 and CD98hc. CD44v9 and CD98hc binds to and stabilizes $\mathrm{xCT}$. CSCs maintain the low level of ROS and escape from senescence, apotosis, Autophagy, differentiation. For complete cancer therapy, it's important to develop the inhibitors of CD44v9, xCT, CD98hc and CD981c

cancer stem cells, thereby enhancing the resistance of such cells to oxidative stress.

We irradiated HNSCC cell lines. The expression of CD44v9 and CD98hc were increased (Figure 1). CD44v9 and CD98hc is the marker of cancer stem cells and radio-sensitivity. Incomplete radiotherapy can lead to cancer stem cell population expansion. CD44v9 and CD98hc might thus be a target for more efficient treatment in HNSCC.

\section{References}

1. Prince ME, Sivanandan R, Kaczorowski A, Wolf GT, Kaplan MJ, et al. (2007) Identification of a subpopulation of cells with cancer stem cell properties in head and neck squamous cell carcinoma. Proc Natl Acad Sci U S A 104: 973-978. [Crossref]

2. Kawasaki Y, Omori Y, Yamada T (2017) Increased Expression of CD44v9, Cancer Stem Cell Marker, in Head and Neck Squamous Cell Carcinoma after Irradiation. Int Cancer Oncol 4: 225-230.

3. Martens-de Kemp SR, Brink A, Stigter-van Walsum M, Damen JM, Rustenburg F, et al. (2013) CD98 marks a subpopulation of head and neck squamous cell carcinoma cells with stem cell properties. Stem Cell Res 10: 477-488. [Crossref]
Copyright: (C)2018 Kawasaki Y. This is an open-access article distributed under the terms of the Creative Commons Attribution License, which permits unrestricted use, distribution, and reproduction in any medium, provided the original author and source are credited.
${ }^{\star}$ Correspondence to: Yohei Kawasaki, Department of Otorhinolaryngology, Head and Neck Surgery, Akita University Graduate School of Medicine, 1-11 Hondo, Akita, 010-8543, Japan, Tel: +81 18-884-6171, Fax: +81 18-8362602, E-mail: kawa0807@med.akita-u.ac.jp

Received: June 03, 2018; Accepted: June 22, 2018; Published: June 25, 2018 